\title{
Appendiceal Neuroendocrine, Goblet and Signet-Ring Cell Tumors: A Spectrum of Diseases with Different Patterns of Presentation and Outcome
}

\author{
Walid Shaib, MD ${ }^{1}$ \\ Kavya Krishna, MD² \\ Sungjin Kim, $\mathrm{PhD}^{3}$ \\ Michael Goodman, MD, $\mathrm{PhD}^{4}$ \\ Jonathan Rock, MD 5 \\ Zhengjia Chen, $\mathrm{PhD}^{3}$ \\ Edith Brutcher, NP1 \\ Charles III Staley, MD ${ }^{6}$ \\ Shishir K. Maithel, MD \\ Samih Abdel-Missih, MD \\ Bassel F. El-Rayes, MD ${ }^{1}$ \\ Tanios Bekaii-Saab, MD²
}

\begin{abstract}
Purpose
Appendiceal tumors are a heterogeneous group of diseases that include typical neuroendocrine tumors (TNET), goblet cell carcinoids (GCC), and atypical GCC. Atypical GCC are classified into signet-ring cell cancers (SRCC) and poorly differentiated appendiceal adenocarcinoids. The prognosis and management of these diseases is unclear because there are no prospective studies. The aim of this study is to assess the characteristics and outcome of appendiceal TNET, GCC, and SRCC patients.
\end{abstract}

\section{Materials and Methods}

Appendiceal TNET, GCC, and SRCC patients diagnosed between 1973 and 2011 were identified in the Surveillance Epidemiology and End Results (SEER) database. Demographics, type of surgery, and clinicopathologic characteristics were collected. Survival functions were estimated by the Kaplan-Meier method, and log-rank test was used to assess the difference in overall survival (OS) among the three histologies.

\section{Results}

The SEER database yielded 1,021 TNET patients, 1,582 with GCC, and 534 SRCC patients. TNET presented at a younger age $(p<0.001)$. Patients with SRCC presented with advanced stage disease $(p<0.001)$. The median OS (mOS) for GCC and TNET patients was not reached; mOS for SRCC was 24 months. Multivariate analysis stratified for stage revealed significantly longer survival for TNET and GCC than SRCC $(p<0.001)$.

\section{Conclusion}

This is the largest report to date for appendiceal neuroendocrine tumor patients, suggesting a spectrum of diseases with different characteristics and outcomes. In this report, we present a treatment approach for this complex spectrum of disease, based on the experience of Ohio State and Emory Universities investigators.

E-mail: wshaib@emory.edu

\section{Key words}

Appendiceal neoplasms, Neuroendocrine tumors, Goblet cells, Signet ring, Survival, Disease management 


\section{Introduction}

Neuroendocrine tumors (NET) are the most common neoplasms of the appendix. These tumors are classified as typical NET (TNET), goblet cell carcinoid (GCC), and atypical GCC histologies. Atypical GCC is defined in the literature as mixed adenoneuroendocrine carcinomas. Ex-goblet or composite-goblet are further classified into signet ring cell carcinoid (SRCC) and poorly differentiated adenocarcinoid of the appendix [1]. Nomenclature and classification of disease are undecided. Appendiceal GCCs are rare tumors constituting $2.5 \%-5 \%$ of all primary appendiceal neoplasms. These tumors have a distinctive morphology showing tight clusters of cells with compact nuclei and abundant intracytoplasmic mucin resembling goblet or signet ring cells often with admixed enterochromaffin cells [2]. Pathologic features of GCC include presence of large mucin filled cells with crescent nuclei arranged in small clumps or rosettes mixed with cells of typical carcinoid appearance that stain positive for chromogranin A [3]. The outcome of appendiceal NET is influenced by the histologic features of the disease. Patients with TNET have a 5-year survival ranging from $60 \%$ to $84 \%$ $[4,5]$, with the most common site of metastasis being the liver. On the other hand, atypical GCC have a more aggressive clinical course with an increased incidence of lymph node and distant metastases, along with a lower 5-year survival ranging from $36 \%$ to 56\% [5-7]. Current management of GCC and atypical GCC is based on very limited data from small single institutional experiences.

The rarity of appendiceal NET, GCC, and SRCC limits the ability to conduct appropriate randomized clinical trials to explore the optimal management. To assess the role of clinicopathologic features in survival of NET, GCC, and SRCC patients, the outcome of cases reported to the National Cancer Institute's Surveillance Epidemiology and End Results (SEER) program was evaluated. Furthermore, to characterize the management of NET, GCC, and SRCC, a treatment strategy based on results of current analysis, published literature and institutional experience is suggested.

\section{Materials and Methods}

\section{Patients}

SEER data collected between 1973 and 2011 was used to identify cases with appendiceal TNET, GCC, and SRCC. The SEER registry data collection began in the early 1970s and gradually expanded from the original nine to the current 18

Table 1. SEER data patient characteristics for TNET, GCC, and SRCC appendiceal tumors

\begin{tabular}{|c|c|c|c|c|}
\hline Characteristic & TNET $(n=1,021)$ & GCC $(n=1,582)$ & $\operatorname{SRCC}(n=534)$ & p-value ${ }^{a)}$ \\
\hline Age (yr) & $41(9-89)$ & $54.5(10-99)$ & $57(25-90)$ & $<0.001$ \\
\hline \multicolumn{5}{|l|}{ Race } \\
\hline White & $812(79.5)$ & $1,300(82.2)$ & $425(79.6)$ & 0.11 \\
\hline Black & $77(7.5)$ & $133(8.4)$ & $42(7.8)$ & \\
\hline Other & $114(11.2)$ & $138(8.7)$ & $65(12.2)$ & \\
\hline Missing & $18(1.8)$ & $11(0.7)$ & $2(0.4)$ & \\
\hline \multicolumn{5}{|l|}{ Sex } \\
\hline Female & $676(66.2)$ & $768(48.5)$ & $328(61.4)$ & $<0.001$ \\
\hline Male & $345(33.8)$ & $814(51.5)$ & $206(38.6)$ & \\
\hline \multicolumn{5}{|l|}{ Stage } \\
\hline Localized & $578(56.6)$ & $927(58.6)$ & $90(16.8)$ & $<0.001$ \\
\hline Regional & $300(29.4)$ & $408(25.8)$ & $116(21.7)$ & \\
\hline Distant & $102(10)$ & $219(14.1)$ & $321(60.1)$ & \\
\hline Missing & $41(4)$ & $28(1.8)$ & $7(1.3)$ & \\
\hline \multicolumn{5}{|l|}{ Surgery } \\
\hline Yes & $854(83.6)$ & $1,382(87.3)$ & $420(78.6)$ & $<0.001$ \\
\hline No & 67 (11.6) & $82(5.2)$ & $9(1.7)$ & \\
\hline Missing & $100(9.8)$ & $118(7.4)$ & $105(19.7)$ & \\
\hline
\end{tabular}

Values are presented as median (range) or number (\%). SEER, Surveillance Epidemiology and End Results; TNET, typical neuroendocrine tumor; GCC, goblet cell carcinoid; SRCC, signet-ring cell cancer. ${ }^{\text {a) }}$ p-value is calculated by Kruskal-Wallis test for age; chi-square test for race. 
Table 2. Summary of the type of surgery done for each histology at different stages for appendiceal TNET, GCC, and SRCC

\begin{tabular}{|lccc|}
\hline Type of surgery & TNET & GCC & SRCC \\
\hline Localized & 510 & 845 & 81 \\
$\quad$ Appendectomy & $40(7.8)$ & $42(5)$ & $3(3.7)$ \\
\hline Right hemicolectomy & $256(50.2)$ & $753(87)$ & $73(90.1)$ \\
\hline Surgery NOS & $214(43)$ & $50(5.9)$ & $5(6.2)$ \\
\hline Regional & 273 & 375 & 108 \\
$\quad$ Appendectomy & $7(2.6)$ & $10(2.7)$ & $2(1.8)$ \\
\hline Right hemicolectomy & $193(70.7)$ & $352(93.9)$ & $105(97.2)$ \\
\hline Surgery NOS & $73(26.7)$ & $13(3.5)$ & $1(0.9)$ \\
\hline Distant & & & 231 \\
\hline Debulking surgery & 71 & 162 & 23 \\
\hline
\end{tabular}

Values are presented as number (\%). TNET, typical neuroendocrine tumor; GCC, goblet cell carcinoid; SRCC, signet-ring cell cancer; NOS, not otherwise specified.

registries that now account for over a quarter of the United States population [6].

Eligibility criteria included International Classification of Diseases for Oncology third edition (ICD-O-3) codes for primary site of appendix and histologic types of TNET (8240, $8241,8242,8246$, and 8270), GCC (8243, 8244, 8245, and 8249), and SRCC (8490). Information regarding age at diagnosis, sex, race, year of diagnosis, grade, histology, tumor location, type of surgery, vital status and duration of follow-up, was extracted from the SEER database.

\section{Statistical analysis}

The patients' characteristics were compared among three histologic types: TNET, GCC, and SRCC by chi-square test for race, sex, and stage, and Kruskal-Wallis test for age. Survival functions were estimated by the Kaplan-Meier method and log-rank test was used to assess the difference in overall survival (OS) between three histologic types: TNET, GCC, and SRCC [8]. Univariate survival analysis for each covariate was carried out using the Cox proportional hazards model [9]. The proportional hazard assumption was checked. The multivariate survival analysis of histology was conducted after adjusting for age, race, and sex using a backward variable selection method with an alpha level of removal of 0.1. The model was stratified by stage since there was an interaction effect between histology and stage on OS. The SAS ver. 9.3 (SAS Institute Inc., Cary, NC) was used for data analyses. Null hypotheses of no difference were rejected if p-values were less than 0.05 , or, equivalently, if the $95 \%$ confidence intervals (CIs) of risk point estimates excluded 1.

\section{Results}

\section{Characteristics of patients with TNET, GCC, and SRCC}

The SEER database yielded 1,021 TNET patients, 1,582 with GCC, and 534 SRCC patients. Between 1973 and 2011, the incidence of TNET, GCC, and SRCC increased. In 2011, the incidence of TNET reached 6.7, GCC was 0.3, and SRCC was two patients per 100,000 persons. Baseline characteristics are compared between appendiceal TNET, GCC, and SRCC in Table 1. Significant differences in age at presentation ( $p<0.001)$, sex distribution $(p<0.001)$, surgery $(\mathrm{p}<0.001)$, type of surgery (appendectomy, right hemicolectomy, and surgery not otherwise specified) $(\mathrm{p}<0.001)$, and stage $(\mathrm{p}<0.001)$ were observed between the TNET, GCC, and SRCC. TNET patients presented younger (median age of 41 vs. 54.5 in GCC and 57 years in SRCC). Female patients constituted a higher proportion among TNET cases $(66.2 \%$ vs. $61.4 \%$ of SRCC and $48.5 \%$ of GCC). Advanced stage disease was more common in SRCC patients $(60.9 \%$ vs. $14.1 \%$ in TNET and $10.4 \%$ in GCC). A higher proportion of white patients was observed in all three histologies, but the difference was not statistically significant $(\mathrm{p}=0.11)$.

Surgery was performed in $839(82.6 \%)$ of the TNET patients, $1,365(86.4 \%)$ of the GCC, and $419(78.6 \%)$ of the SRCC patients, and these differences were statistically significant $(p<0.001)$. Appendectomy was performed in 52 of patients with TNET (5.9\%) as compared to 54 of the GCC $(3.9 \%)$, and 9 of the SRCC (2.1\%). Right hemicolectomy was performed in 484 of the TNET $(54.9 \%), 1,208$ of the GCC $(86.4 \%)$, and 301 of the SRCC patients $(70.7 \%)$. The differences in type of surgery were significantly different among the three histologies $(\mathrm{p}<0.001)$. Table 2 summarizes the type of surgery based on histology and stage. 
Table 3. Univariate and multivariate analysis showing differences in histology, race, sex, age, and stage

\begin{tabular}{|c|c|c|c|c|}
\hline \multirow{2}{*}{ Covariate } & \multicolumn{2}{|c|}{ Univariate analysis } & \multicolumn{2}{|c|}{ Multivariate analysis } \\
\hline & $\mathrm{HR}(95 \% \mathrm{CI})$ & p-value & $\mathrm{HR}^{\mathrm{a})}(95 \% \mathrm{CI})$ & p-value \\
\hline \multicolumn{5}{|l|}{ Histology } \\
\hline GCC & $0.22(0.19-0.26)$ & $<0.001$ & $0.59(0.48-0.72)$ & $<0.001$ \\
\hline TNET & $0.12(0.10-0.15)$ & & $0.41(0.31-0.55)$ & \\
\hline SRCC & 1 (reference) & & 1 (reference) & \\
\hline \multicolumn{5}{|l|}{ Race } \\
\hline African American & $1.14(0.88-1.47)$ & 0.012 & $0.59(0.48-0.72)$ & 0.083 \\
\hline Caucasian & $1.37(1.11-1.70)$ & & $0.41(0.31-0.55)$ & \\
\hline Other & 1 (reference) & & 1 (reference) & \\
\hline Sex & & & b) & \\
\hline Female & $1.06(0.92-1.22)$ & 0.391 & & - \\
\hline Male & 1 (reference) & & & \\
\hline Age & $1.05(1.04-1.05)$ & $<0.001$ & a) & - \\
\hline Stage & & & a) & \\
\hline Localized & $0.07(0.06-0.08)$ & $<0.001$ & & - \\
\hline Regional & $0.16(0.13-0.19)$ & & & \\
\hline Distant & 1 (reference) & & & \\
\hline Surgery type ${ }^{c)}$ & & & 0.062 & \\
\hline Appendectomy & $0.19(0.12-0.31)$ & $<0.001$ & $1.24(0.71-2.18)$ & - \\
\hline Hemicolectomy & $0.24(0.20-0.30)$ & & $0.81(0.65-1.02)$ & \\
\hline Surgery NOS & 1 (reference) & & 1 (reference) & \\
\hline
\end{tabular}

HR, hazard ratio; CI, confidence interval; GCC, goblet cell carcinoid; TNET, typical neuroendocrine tumor; SRCC, signet-ring

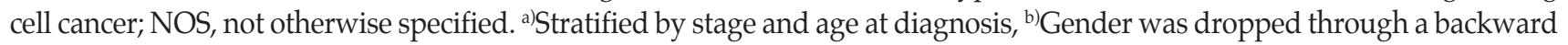
variable selection method ( $\mathrm{p}>0.1)$, c) Partial colectomy was classified as hemicolectomy.

\section{Survival outcome of patients with TNET, GCC, and SRCC}

The median overall survival ( $\mathrm{mOS}$ ) for appendiceal SRCC was 24 months. The mOS for GCC and TNET were not reached at the time of this analysis. Comparing survival among the different histologies, TNET had a survival advantage over GCC (hazard ratio [HR], 0.56; 95\% CI, 0.45 to 0.69 ; $\mathrm{p}=0.005)$, which had a better survival over SRCC histology (HR, 0.22; 95\% CI, 0.19 to 0.26; p < 0.001) (Table 3). In each stage, TNET and GCC had significant survival advantages over SRCC (Figs. 1-3). In the localized stage, mOS was not reached for any of the three histologies. Comparing SRCC, the HR for survival was $0.26(0.15-0.46$; $\mathrm{p}<0.001)$ for TNET and $0.42(0.26-0.69 ; \mathrm{p}<0.001)$ for GCC. For regional stage disease, the mOS for SRCC was 35 months (95\% CI, 30 to 45), while mOS for GCC and TNET were not reached. The TNET regional disease stage patients had survival advantage over GCC (HR, 0.37; 95\% CI, 0.24 to 0.59 ; p < 0.001). GCC had better survival compared to SRCC patients with regional disease stage (HR, 0.29; 95\% CI, 0.21 to $0.40 ; \mathrm{p}<0.001$ ). For distant disease stage, mOS was 32 (95\% CI, 13 to not reached) for
TNET, 23 (95\% CI, 18 to 28) for GCC, and 15 months (95\% CI, 13 to 18) for SRCC. In this group, TNET patients had survival advantage over GCC (HR, 0.61; 95\% CI, 0.44 to 0.83 ; $\mathrm{p}=0.002)$. GCC patients survived better compared to SRCC patients with distant disease (HR, 0.73; 95\% CI, 0.60 to 0.90 ; $\mathrm{p}=0.003$ ).

After adjusting for age, stage, and histology, there was a statistically significant difference in survival for SRCC patients treated with hemicolectomy compared to appendectomy $(p=0.01)$. There was no significant difference in survival for TNET and GCC patients based the type of surgery $(p=0.21$ and $p=0.94$, respectively). In the multivariate analysis stratified by stage and age, there was a statistically significant difference in survival favoring TNET (HR, 0.41; 95\% CI, 0.31 to 0.55$)$ and GCC (HR, $0.59 ; 95 \%$ CI, 0.48 to 0.72$)$ over SRCC.

\section{Discussion}

Appendiceal TNET, GCC and SRCC are distinct clinico- 


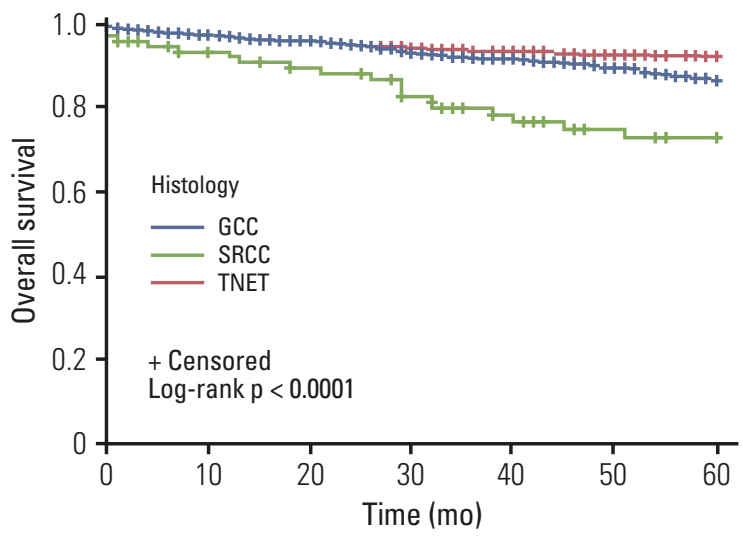

Fig. 1. Kaplan-Meier curves of localized appendiceal cancers comparing survival in different histologies. Localized typical neuroendocrine tumor (TNET) (hazard ratio [HR], 0.26 ; $95 \%$ confidence interval [CI], 0.15 to 0.46 ; $\mathrm{p}<0.001$ ) and goblet cell carcinoid (GCC) tumors (HR, $0.42 ; 95 \%$ CI, 0.26 to $0.69 ; \mathrm{p}=0.001$ ) have survival advantage, as compared with signet-ring cell cancer (SRCC) histology.

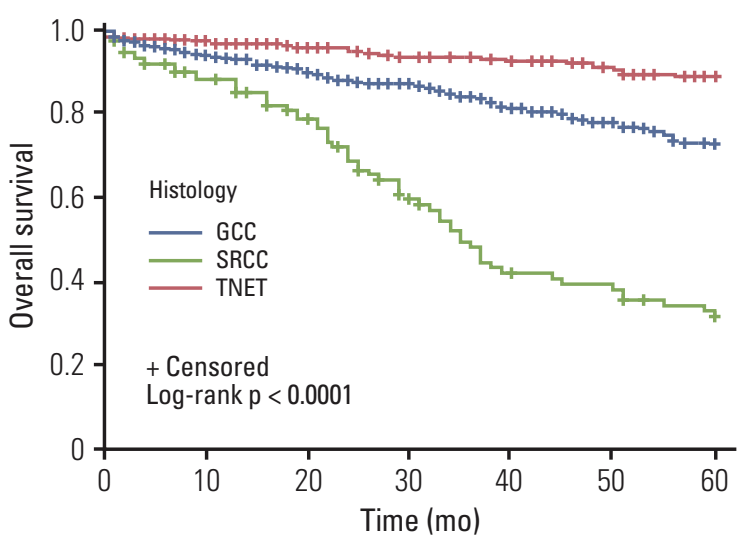

Fig. 2. Kaplan-Meier curves of regional disease comparing survival in different histologies. Regional typical neuroendocrine tumor (TNET) has survival advantage over goblet cell carcinoid (GCC) tumors (hazard ratio [HR], 0.37 ; 95\% confidence interval [CI], 0.24 to $0.59 ; \mathrm{p}<0.001$ ), which has a better survival, in turn, as compared to signet-ring cell cancer (SRCC) histology (HR, 0.29; 95\% CI, 0.21 to 0.40; p $<0.001)$.

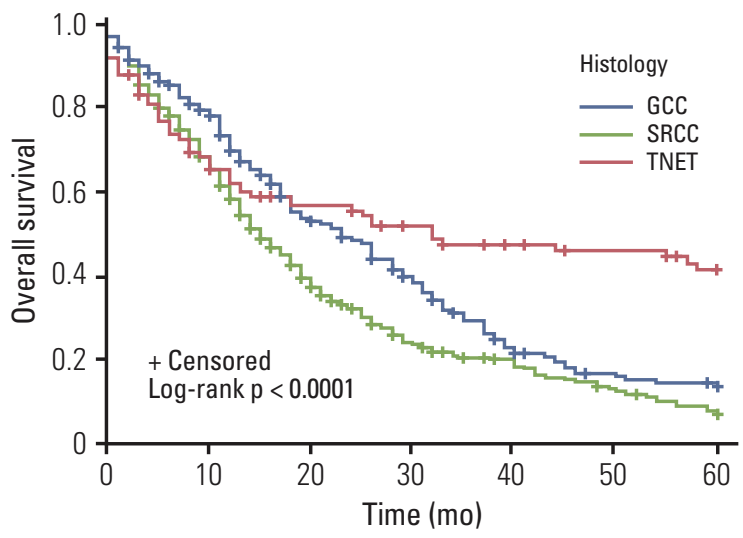

Fig. 3. Kaplan-Meier curves of distant disease comparing survival in different histologies. Distant typical neuroendocrine tumor (TNET) has survival advantage over goblet cell carcinoid (GCC) tumors (hazard ratio [HR], 0.61; 95\% confidence interval [CI], 0.44 to 0.83 ; $p=0.002$ ), which has a better survival, in turn, as compared to signet-ring cell cancer (SRCC) histology (HR, 0.73; 95\% CI, 0.60 to 0.90 ; $\mathrm{p}=0.003$ ).

pathologic entities. The analysis of the SEER registry sample confirms the differences in presentation and outcome of these diseases. TNET tend to occur at a younger age and has a less aggressive clinical course, early stage at presentation and significantly improved OS. At the other end of the disease spectrum, SRCC tend to occur in older patients. The aggressive nature of SRCC is reflected by the high risk of distant metastasis at diagnosis, and worse survival outcomes even when controlled for stage.

The reported sex distribution in TNET ranges from a female preponderance ( $63 \%$ to $73 \%$ ) to evenly distributed $[4,10]$. Similarly for GCC, literature reports range from female gender predominance $[1,11,12]$, to equal distribution $[4,10,11]$. Most of these series are based on small numbers of patients from single institution studies. The current report confirms, using a large national database, that there are gender differences in distribution of TNET, GCC, and SRCC $(\mathrm{p}<0.001)$. For SRCC histology, we confirmed a higher prevalence amongst women in this SEER analysis as compared to GCC histology, consistent with a previous report [1]. Additionally, appendiceal SRCC appear to be clinically similar to right-sided, microsatellite unstable, signet ring cell colon adenocarcinoma with respect to gender distribution, age of diagnosis and outcome. This raises the question whether appendiceal SRCC and right colon adenocarcinomas behave more like a single disease entity distinct from other colorectal cancer (CRC) adenocarcinoma and appen- 
Table 4. Summary of the differences in the NANETS and ENETS guidelines for treatment of TNET and GCC patients

\begin{tabular}{|c|c|c|}
\hline & NANETS [17] & ENETS [18] \\
\hline \multicolumn{3}{|l|}{ TNET } \\
\hline \multirow[t]{8}{*}{ Localized } & Appendectomy & Appendectomy \\
\hline & $\begin{array}{l}<1 \mathrm{~cm} \text {, no lymphovascular or } \\
\text { mesoappendiceal involvement }\end{array}$ & $\begin{array}{l}\text { Size }<\text { or }=1 \text {, absence of subserosal or } \\
\text { mesoappendix involvement }\end{array}$ \\
\hline & Right hemicolectomy & Right hemicolectomy \\
\hline & Base of the appendix & Involved margins \\
\hline & $>2 \mathrm{~cm}$ & $>2 \mathrm{~cm}$ mass \\
\hline & Intermediate grade & Grade 2 disease \\
\hline & Lymph node involvement & Base of the appendix involved \\
\hline & No adjuvant treatment is recommended & No adjuvant treatment is recommended \\
\hline Metastatic & As midgut & As midgut \\
\hline \multicolumn{3}{|l|}{ GCC } \\
\hline \multirow[t]{4}{*}{ Localized } & - & $\begin{array}{l}\text { GCC is considered mixed } \\
\text { adeno-neuroendocrine carcinoma }\end{array}$ \\
\hline & & Right hemicolectomy \\
\hline & & $\begin{array}{l}\text { Always recommended even after } \\
\text { appendectomy (within } 3 \text { months of } \\
\text { appendectomy) }\end{array}$ \\
\hline & & $\begin{array}{l}\text { Salpingo-oophorectomy recommended } \\
\text { in female patients }\end{array}$ \\
\hline Metastatic & - & $\begin{array}{l}\text { Treat as adenocarcinoma with } \\
\text { fluoropyrimidine-based chemotherapy }\end{array}$ \\
\hline
\end{tabular}

NANETS, North American Neuroendocrine Tumor Society; ENETS, European Neuroendocrine Tumor Society; TNET, typical neuroendocrine tumor; GCC, goblet cell carcinoid.

diceal GCC. This apparent difference in clinical behavior will require further characterization through genomic analysis of CRC SRCC, appendiceal SRCC and typical GCC. Hence, a molecularly based classification may facilitate prognostication and perhaps target identification for future clinical trials.

The analysis of the SEER data confirms that histology and stage at presentation are the major determinants of outcome. The high risk of metastatic disease in the SRCC patients confirms the aggressive clinical behavior of this tumor. The rate of metastasis at diagnosis in SRCC histology ranges from $14 \%$ [4] to $63 \%$ [1]. The survival advantage for TNET and GCC over SRCC persisted after controlling for the difference in stage distribution. Similar observations were reported with 5-year survival of patients with advanced stage GCC, SRCC and poorly differentiated adenocarcinoid tumor being $100 \%, 38 \%$, and $0 \%$, respectively [1].

Given their rarity, there is no consensus on the management of appendiceal TNET, GCC, or SRCC. The treatments employed included surgical resection and cytoreduction of primary tumor and metastatic sites, intraperitoneal chemotherapy and systemic fluorouracil-based chemotherapy. Debulking surgery and hyperthermic intraperitoneal chemotherapy treatment is not well-established in appendiceal NET, GCC, and SRCC tumors, although it improves appendiceal mucinous adecarcinoma $[13,14]$. All of these treatment options lack evidence of efficacy. Clinically, the management decisions are usually based on histologic subtype and stage, as well as the patient's performance status. Early stage TNET, GCC, or SRCC should be managed surgically, although the extent of surgery is an open question. Historically, the accepted surgical dogma was that simple appendectomy is sufficient for resection of TNET less than $2 \mathrm{~cm}$ [15]. Recent reports demonstrated that appendiceal TNET measuring less than $2 \mathrm{~cm}$ may have regional nodal involvement, raising the question whether a more extensive surgery than simple appendectomy is required irrespective of size [16]. These observations are further supported by a SEER analysis where $32.8 \%$ of patients with NET less than 2 $\mathrm{cm}$ in size (20/61) had lymph node metastasis [4]. The North American Neuroendocrine Tumor Society (NANETS) [17] and European Neuroendocrine Tumor Society (ENETS) [18] guidelines suggest right hemicolectomy for all tumors $>2 \mathrm{~cm}$ or presence of deep mesoappendiceal invasion, positive or unclear margins, higher proliferative rate (grade 2), angi- 


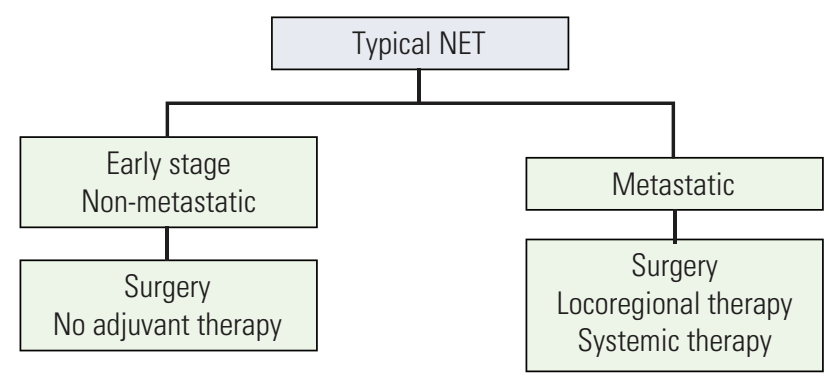

A

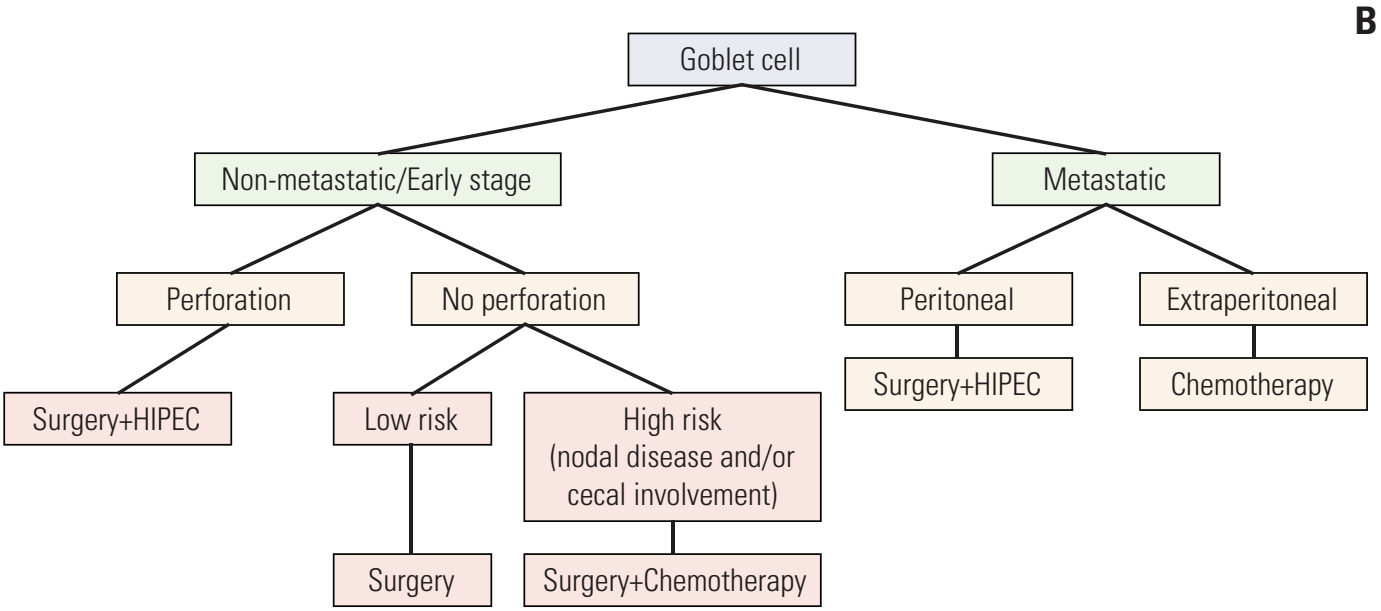

B

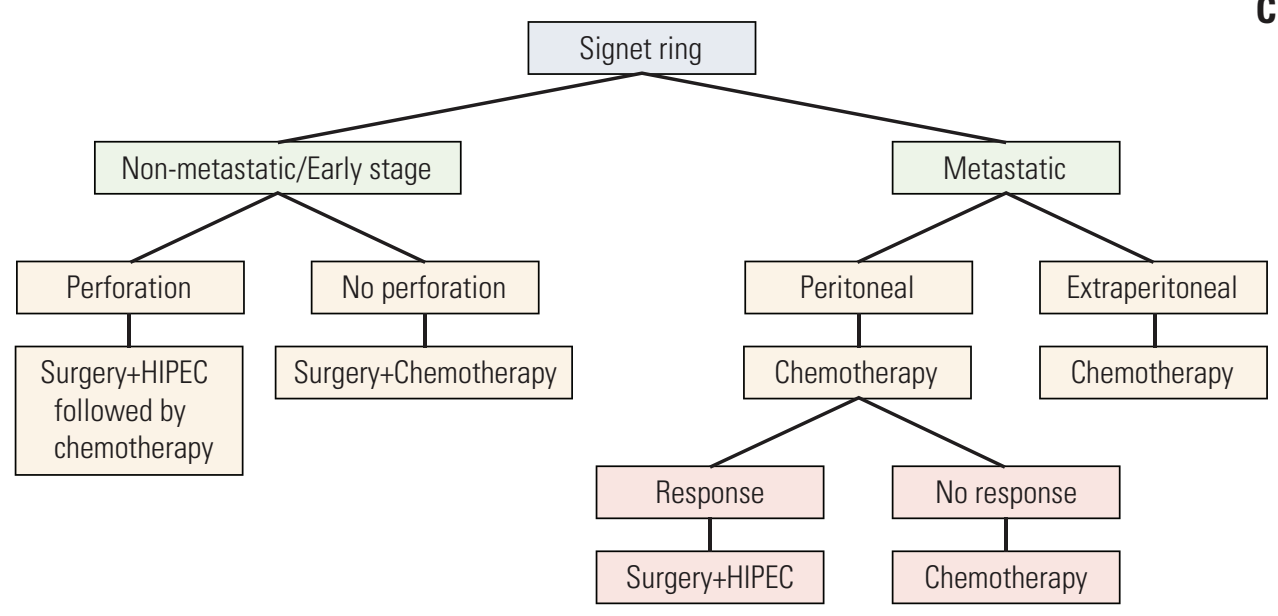

Fig. 4. Summary of the proposed treatment algorithm for typical NET (A), goblet cell carcinoid (B), and signet-ring cell cancer (SRCC) (C) tumors. Chemotherapy is fluropyrimidine based. NET, neuroendocrine tumor; HIPEC, hyperthermic intraperitoneal chemotherapy. ${ }^{a} \mathrm{HIPEC}$ treatment treatment is controversial in SRCC. 
olymphatic invasion, and mixed histology, irrespective of tumor size. There is no accepted consensus regarding surgical resection for GCC or SRCC tumors. While simple appendectomy may be adequate for early stage GCC $[19,20]$, cecal involvement or high mitotic count index should be an indication for right hemicolectomy $[19,21,22]$. Surgery for SRCC should always involve a right hemicolectomy due to the high likelihood of lymph node metastasis, irrespective of the size of the primary appendiceal mass. This is supported by our analysis of the SEER data that indicates superior survival for patients with SRCC who undergo right hemicolectomy. The role of surgical resection of the ovaries in female patients with localized SRCC or GCC remains controversial $[1,12,22]$. A summary of the NANETS [17] and ENETS [18] guidelines is provided in Table 4.

Unlike CRC adenocarcinoma, the role of adjuvant therapy is not established for TNET, GCC, or SRCC. Based on our analysis, patients with TNET have an excellent OS and therefore adjuvant therapy is not indicated. On the other hand, given the high risk of systemic metastasis in SRCC, we recommend offering adjuvant therapy for all patients undergoing resection. In our analysis of the SEER sample, the outcome of patients with early stage GCC appears favorable, suggesting that patients with GCC should be considered for adjuvant therapy only if they have high risk features such as cecal invasion, perforation, or lymph node involvement. Management of advanced stage disease in TNET should be similar to midgut NET. For GCC patients with advanced stage disease, options of treatments include peritoneal debulking with intraperitoneal chemotherapy for patient with limited peritoneal disease or systemic fluorouracilbased chemotherapy. For SRCC patients, our recommendations include treating with systemic fluorouracil-based chemotherapy initially and only consider peritoneal resection for patients with good response to initial therapy. A summary of the proposed treatment algorithm is provided in Fig. 4.
Predictive and prognostic biomarkers are not well defined for these diseases. In an attempt to identify gene variations between appendiceal mucinous adenocarcinoma and GCC, we profiled nine GCC samples using second-generation gene sequencing. Only one patient with GCC $(11 \%)$ had KRAS mutation, and two had TP53 mutation; MYC, SMAD4, and APC mutations were absent in GCC [23]. Stancu et al. [24] and Dimmler et al. [25] proved the absence of KRAS mutations in 16 and 14 GCC samples. In the light of its rarity, molecular differentiation markers for appendiceal TNET, GCC, and SRCC were never studied. Further confirmation with larger studies is needed to evaluate pathologic genomic sequencing for the three histologies in order to detect differences in survival and possible future biomarkers that predict response to specific target treatments.

\section{Conclusion}

This is the largest report to date for patients with appendiceal NET. The SEER registry findings confirm the distinct clinical entities of TNET, GCC, and SRCC with respect to presentation and outcome. Careful evaluation of the morphologic features and appropriate pathologic classification are crucial for treatment. A treatment strategy is presented based on the experience of both institutions.

\section{Conflicts of Interest}

Conflict of interest relevant to this article was not reported.

\section{References}

1. Tang LH, Shia J, Soslow RA, Dhall D, Wong WD, O'Reilly E, et al. Pathologic classification and clinical behavior of the spectrum of goblet cell carcinoid tumors of the appendix. Am J Surg Pathol. 2008;32:1429-43.

2. Burke AP, Sobin LH, Federspiel BH, Shekitka KM, Helwig EB. Goblet cell carcinoids and related tumors of the vermiform appendix. Am J Clin Pathol. 1990;94:27-35.

3. Sugarbaker PH. Cytoreductive surgery and perioperative intraperitoneal chemotherapy: a new standard of care for appendiceal mucinous tumors with peritoneal dissemination.
Clin Colon Rectal Surg. 2005;18:204-14.

4. McCusker ME, Cote TR, Clegg LX, Sobin LH. Primary malignant neoplasms of the appendix: a population-based study from the surveillance, epidemiology and end-results program, 1973-1998. Cancer. 2002;94:3307-12.

5. Wang HL, Dhall D. Goblet or signet ring cells: that is the question. Adv Anat Pathol. 2009;16:247-54.

6. National Cancer Institute. SEER as a research resource. Bethesda, MD: National Institutes of Health; 2010.

7. Abt AB, Carter SL. Goblet cell carcinoid of the appendix: an 
ultrastructural and histochemical study. Arch Pathol Lab Med. 1976;100:301-6.

8. Kalbfleisch JD, Prentice RL. The statistical analysis of failure time data. New York: John Wiley and Sons; 1980.

9. Cox DR. Regression models and life-tables. J R Stat Soc Ser B Methodol. 1972;34:187-220.

10. Pahlavan PS, Kanthan R. Goblet cell carcinoid of the appendix. World J Surg Oncol. 2005;3:36.

11. Hsu C, Rashid A, Xing Y, Chiang YJ, Chagpar RB, Fournier $\mathrm{KF}$, et al. Varying malignant potential of appendiceal neuroendocrine tumors: importance of histologic subtype. J Surg Oncol. 2013;107:136-43.

12. Pham TH, Wolff B, Abraham SC, Drelichman E. Surgical and chemotherapy treatment outcomes of goblet cell carcinoid: a tertiary cancer center experience. Ann Surg Oncol. 2006;13: 370-6.

13. Shaib WL, Martin LK, Choi M, Chen Z, Krishna K, Kim S, et al. Hyperthermic intraperitoneal chemotherapy following cytoreductive surgery improves outcome in patients with primary appendiceal mucinous adenocarcinoma: a pooled analysis from three tertiary care centers. Oncologist. 2015;20:907-14.

14. Chua TC, Moran BJ, Sugarbaker PH, Levine EA, Glehen O, Gilly FN, et al. Early- and long-term outcome data of patients with pseudomyxoma peritonei from appendiceal origin treated by a strategy of cytoreductive surgery and hyperthermic intraperitoneal chemotherapy. J Clin Oncol. 2012;30: 2449-56.

15. Moertel CG, Weiland LH, Nagorney DM, Dockerty MB. Carcinoid tumor of the appendix: treatment and prognosis. $\mathrm{N}$ Engl J Med. 1987;317:1699-701.

16. Syracuse DC, Perzin KH, Price JB, Wiedel PD, Mesa-Tejada R. Carcinoid tumors of the appendix. Mesoappendiceal extension and nodal metastases. Ann Surg. 1979;190:58-63.
17. Boudreaux JP, Klimstra DS, Hassan MM, Woltering EA, Jensen RT, Goldsmith SJ, et al. The NANETS consensus guideline for the diagnosis and management of neuroendocrine tumors: well-differentiated neuroendocrine tumors of the jejunum, ileum, appendix, and cecum. Pancreas. 2010;39: 753-66.

18. Pape UF, Perren A, Niederle B, Gross D, Gress T, Costa F, et al. ENETS Consensus Guidelines for the management of patients with neuroendocrine neoplasms from the jejunoileum and the appendix including goblet cell carcinomas. Neuroendocrinology. 2012;95:135-56.

19. Park K, Blessing K, Kerr K, Chetty U, Gilmour H. Goblet cell carcinoid of the appendix. Gut. 1990;31:322-4.

20. Edmonds P, Merino MJ, LiVolsi VA, Duray PH. Adenocarcinoid (mucinous carcinoid) of the appendix. Gastroenterology. 1984;86:302-9.

21. Chen V, Qizilbash AH. Goblet cell carcinoid tumor of the appendix: report of five cases and review of the literature. Arch Pathol Lab Med. 1979;103:180-2.

22. Butler JA, Houshiar A, Lin F, Wilson SE. Goblet cell carcinoid of the appendix. Am J Surg. 1994;168:685-7.

23. Goldstein DA, Elvin JA, Wang K, Shaib WL, Rossi MR, Stephens PJ, et al. Comprehensive genomic profiling of cancer of the appendix to reveal new routes to targeted therapies. J Clin Oncol. 2015;33 Suppl 3:608.

24. Stancu M, Wu TT, Wallace C, Houlihan PS, Hamilton SR, Rashid A. Genetic alterations in goblet cell carcinoids of the vermiform appendix and comparison with gastrointestinal carcinoid tumors. Mod Pathol. 2003;16:1189-98.

25. Dimmler A, Geddert H, Faller G. EGFR, KRAS, BRAF-mutations and microsatellite instability are absent in goblet cell carcinoids of the appendix. Pathol Res Pract. 2014;210:274-8. 